\title{
The European Arctic: A Laboratory for Seismo-Acoustic Studies
}

Steven J. Gibbons ${ }^{1}$, Vladimir Asming ${ }^{2}$, Lars Eliasson ${ }^{3}$, Andrei Fedorov ${ }^{2}$, Jan Fyen ${ }^{1}$, Johan Kero $^{3}$, Elena Kozlovskaya ${ }^{4}$, Tormod Kværna ${ }^{1}$, Ludwik Liszka ${ }^{3}$, Sven Peter Näsholm ${ }^{1}$, Tero Raita $^{5}$, Michael Roth ${ }^{1}$, Timo Tiira ${ }^{6}$, Yuri Vinogradov ${ }^{2}$

Steven J. Gibbons, NORSAR PO Box 53, 2027 Kjeller, Norway. (corresponding author)

Vladimir Asming, Kola Regional Seismological Center, Apatity, Russia.

Lars Eliasson, Swedish Institute of Space Physics, Sweden.

Andrei Fedorov, Kola Regional Seismological Center, Apatity, Russia.

Jan Fyen, NORSAR, Norway.

Johan Kero, Swedish Institute of Space Physics, Sweden.

Elena Kozlovskaya, University of Oulu, Oulu, Finland.

Tormod Kværna, NORSAR, Norway.

Ludwik Liszka, Swedish Institute of Space Physics, Sweden.

Sven Peter Näsholm, NORSAR, Norway.

Tero Raita, Sodankylä Geophysical Observatory (University of Oulu), Finland.

Michael Roth, NORSAR, Norway.

Timo Tiira, University of Helsinki, Helsinki, Finland.

Yuri Vinogradov, Kola Regional Seismological Center, Apatity, Russia.

\footnotetext{
${ }^{1}$ NORSAR, Kjeller, Norway.

${ }^{2}$ Kola Regional Seismological Center, Apatity, Russian Federation.

${ }^{3}$ Swedish Institute of Space Physics, Kiruna, Sweden.

${ }^{4}$ University of Oulu, Oulu, Finland.

${ }^{5}$ Sodankylä Geophysical Observatory (University of Oulu, Oulu, Finland).

${ }^{6}$ University of Helsinki, Helsinki, Finland.
} 


\section{INTRODUCTION}

The International Monitoring System (IMS) for verifying compliance with the Comprehensive Nuclear-Test-Ban Treaty (CTBT) comprises sensors associated with four monitoring technologies: seismic, infrasound, hydroacoustic, and radionuclide. The so-called waveform technologies (seismic, infrasound, and hydroacoustic) are used to detect and locate events that could constitute treaty violations. All four technologies may be employed to investigate the nature of events, with the network of radionuclide sensors in place to provide evidence of a nuclear explosion. Historical, political and technical issues surrounding the CTBT are discussed by, e.g. Dahlman et al. (2009) and Dahlman et al. (2011). The global IMS infrasound network (Figure 1) is primarily to detect signals generated by atmospheric nuclear tests.

The IMS infrasound network has been deployed over the last two decades (Christie and Campus, 2010, Brachet et al., 2010) and only with the network approaching completion has a realistic picture of its detection capability emerged (Le Pichon et al. 2009, Green and Bowers, 2010). The detectability of atmospheric signals is governed by a seasonally varying wind-determined anisotropy. In the northern summer, the stratospheric winds blow predominantly East to West, facilitating the detection of infrasound at stations west of sources and inhibiting the detection at stations east of sources. In the northern winter, the winds blow in the opposite direction changing the sense of high and low detectability. The reverse patterns occur in the Southern Hemisphere. There is increasing interest in using infrasound for probing atmospheric structure (e.g. Lalande et al., 2012) and the broader properties and applications of infrasound are discussed by e.g. Evers and Haak (2009) and Hedlin et al. (2012). 


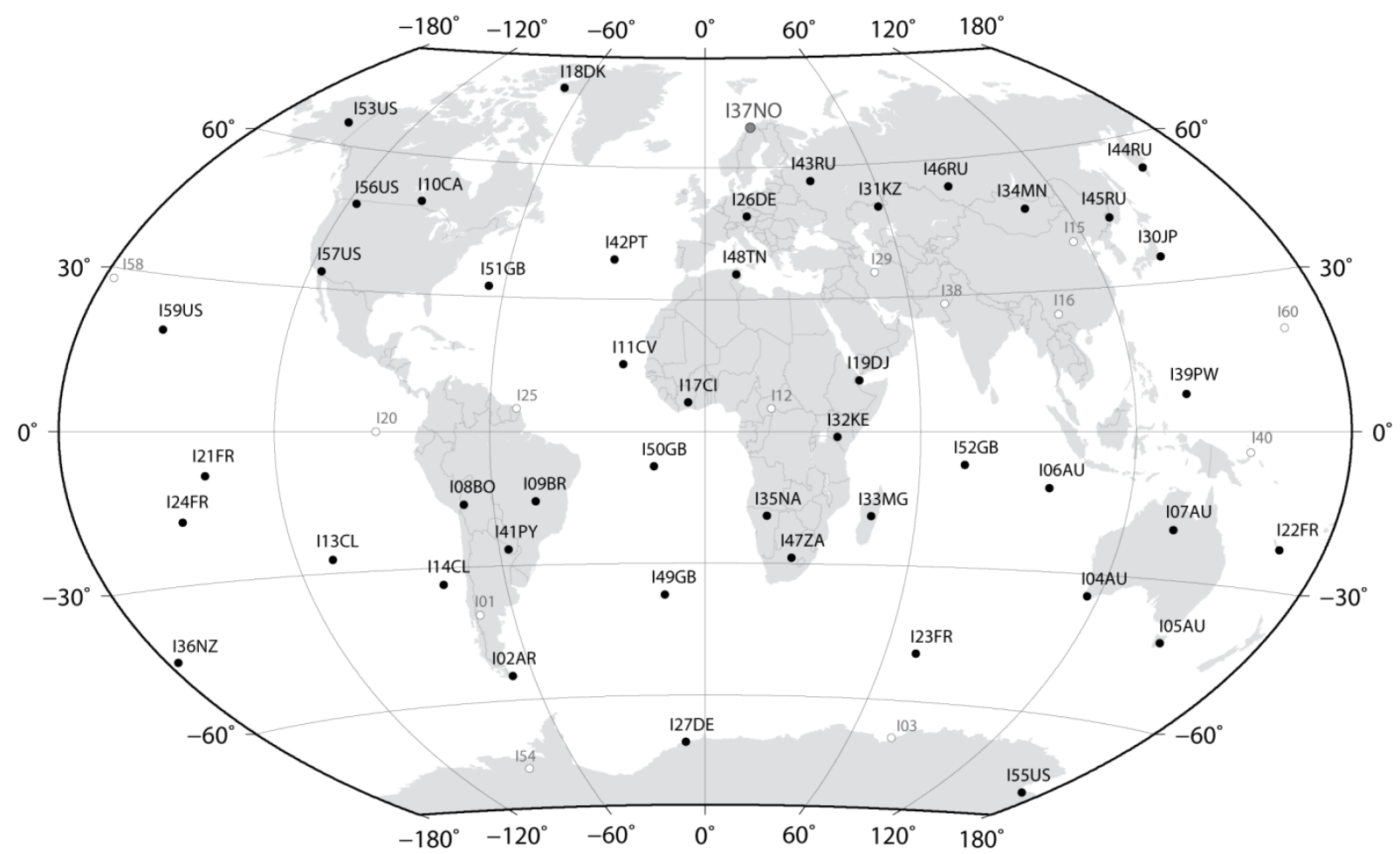

Figure 1 Status of the IMS infrasound network in August 2014. Filled symbols are certified stations sending data to the International Data Center (IDC) in Vienna. White symbols indicate the treaty coordinates of stations planned or under construction.

In October 2013, IS37 (the IMS infrasound array near Bardufoss in northern Norway) came online. IS37, also referred to as I37NO, was certified on December 19, 2013. In addition to filling a clear gap in the global network, IS37 is a key node in the station network covering Europe and the surrounding regions (Figure 2). In addition to IMS infrasound arrays, this region includes many national facilities which comprise a far denser network than the IMS stations alone form. The combined network is capable of detecting and locating considerably smaller events than the global network was designed for (Le Pichon et al., 2008). 


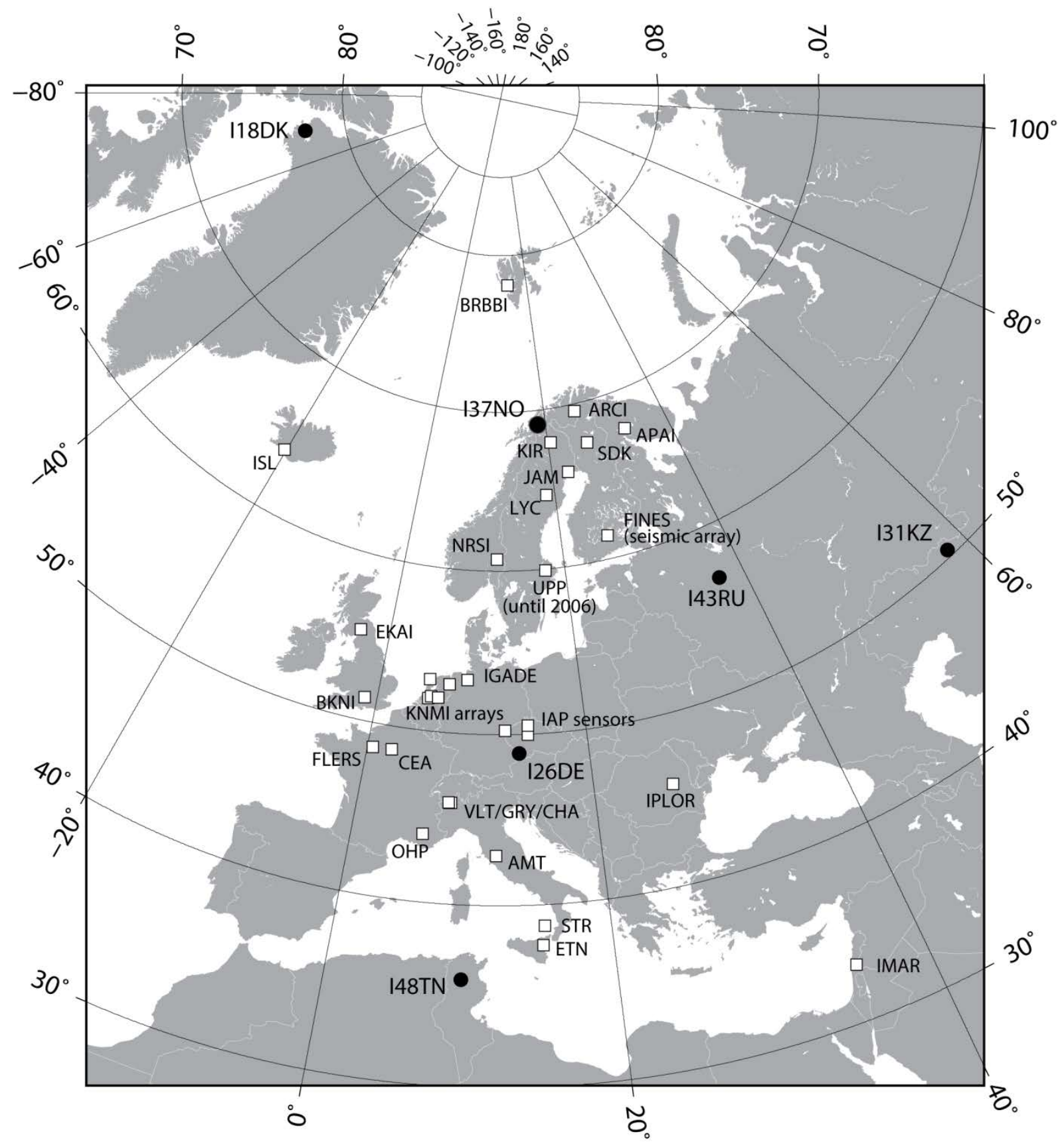

Figure $\mathbf{2}$ Network of infrasound arrays in and surrounding Europe. Filled circles and white squares indicate IMS arrays non-IMS national facilities respectively.

The national facilities have been deployed over several decades with quite diverse objectives. Since the early 1970s, a network of small aperture microphone arrays in Sweden has provided data on long-distance infrasound propagation from e.g. industrial sources (Liszka, 1974), supersonic jets (Liszka, 1978), and volcanos (Liszka and Garcés, 2002). Several infrasound arrays in the Netherlands were deployed from the mid-1990s to detect sonic booms and military activity (Evers, 2008) and numerous small aperture infrasound arrays have been deployed close to volcanos to monitor activity 
from local distances (see e.g. Fee and Matoza, 2013). A seismic-infrasonic station BRBBI at Barentsburg, Svalbard, (Asming et al., 2013) recorded both nearby industrial events and seismoacoustic emissions from calving glaciers. Many of the remaining arrays displayed in Figure 2 have been constructed by co-locating microbarographs with sensors in existing seismometer arrays to investigate infrasound generated by so-called seismo-acoustic events, and to understand the relationship between the seismic and infrasonic wavefields. The advantages of processing these diverse stations in a coordinated approach has been demonstrated in numerous studies considering the monitoring of e.g. volcanic sources (Evers and Haak, 2005; Matoza et al., 2011; Tailpied et al., 2013) and accidental explosions (Evers et al., 2007; Ceranna et al., 2009; Green et al., 2011).

In this paper, we focus on a region with numerous repeating seismo-acoustic sources and an unprecedented number of seismic and infrasonic sensor deployments that have operated continuously for up to several decades: northern Fennoscandia and northwest Russia. We describe both anthropogenic sources of seismic and infrasonic waves in the region and the current station network. In the context of the sensor types and array geometries in operation, we describe the array procedures used to detect and classify infrasound signals. We describe how repeating seismoacoustic events are detected and characterized using seismic data, and provide examples of recordings of the regional infrasonic wavefield generated by these events. We finally provide future perspectives.

\section{THE EUROPEAN ARCTIC: A SEISMO-ACOUSTIC OBSERVATORY}

The stations in Figure 3 have only been processed as a virtual network of arrays for a relatively short time, although some of the stations date back several decades. The collaborative processing of data from these stations has been motivated greatly by the presence of many repeating explosion sources in the region. These events are mostly so-called Ground Truth (GT) events: meaning that the time and location (and sometimes the yield) are known. GT events are crucial in constraining methods for 
numerical simulation of infrasound propagation and atmospheric wind and temperature profiles. Propagation models need to be found that predict infrasound consistently with observations. A review of the history and principles of assessing infrasound network capability using GT events is provided by Green et al. (2010).

The ARCES seismic array comprises 25 sites over a $3 \mathrm{~km}$ aperture and was deployed in 1987 as one of several small aperture arrays optimized to detect and locate small magnitude events at regional distances (e.g. Mykkeltveit et al., 1990). The stations were deployed primarily to detect and identify signals from underground nuclear tests and rapidly it became clear that monitoring at very low thresholds was challenging due to the detection of vast numbers of industrial blasts. A significant effort has been invested in methods for identifying seismic signals from such "legitimate sources" so that each such event can be (semi-)automatically ascribed to a known source with high confidence. Algorithms for autonomous event identification and location exploit both classical array seismology (e.g. Kværna and Ringdal, 1994; Gibbons et al., 2005) and so-called pattern detection: waveform correlation (Harris, 1991; MacCarthy et al., 2008) and empirical matched field processing (Harris and Kværna, 2010). All approaches require calibration against previously confirmed GT events, and a large GT collection project in the European Arctic was initiated to build a regional database of mining events (Harris et al., 2003). 


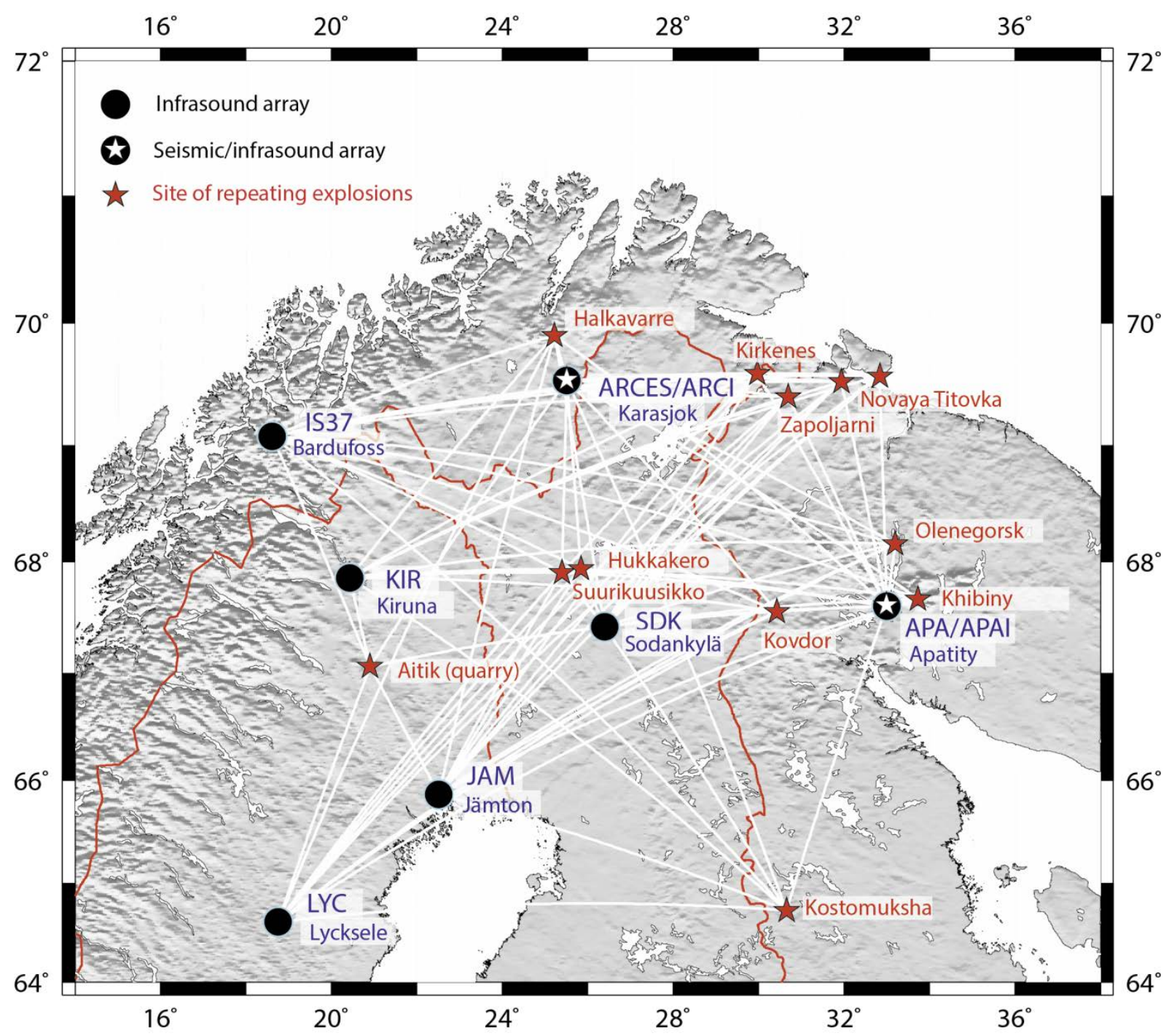

Figure 3 Sources of repeating explosions and sensor arrays that have recorded acoustic signals from these sources. KIR, JAM and LYC are operated by the Swedish Institute of Space Physics (IRF). SDK is operated by the Sodankylä Geophysical Observatory and IRF. ARCES, ARCI and IS37 are operated by NORSAR, and APA/APAI is operated by the Kola Regional Seismological Center.

Later it was understood that many "nuisance events" also generated infrasound, such that systematic recording of source parameters and signals would help understand and calibrate infrasound propagation (e.g. Sorrells et al., 1997; Hagerty et al., 2002). (Stump et al., 2002, point out that infrasound may be a useful discriminant for near-surface explosions.) In particular, events with almost repeating seismic signals were often associated with infrasound signals which varied qualitatively event-to-event: especially with season. A 3-element microbarograph array was installed co-located with seismometers in the small aperture Apatity (seismic) array on the Kola Peninsula, a 
region with many industrial sources. Preliminary infrasound observations from blasts at the different mining clusters in the region are discussed by Vinogradov and Ringdal (2003).

A source of special interest has been the Hukkakero site in northern Finland where the Finnish military carry out repeating blasts to destroy expired ammunition. The event-to-event similarity of the seismic signals mean the signals can be extracted from the background noise using a multichannel correlation detector (Gibbons and Ringdal, 2006) and a summary of seismic and acoustic signals is presented by Gibbons et al. (2007). Infrasound signals were recorded on the ARCES seismic sensors and are of particular interest since, at $180 \mathrm{~km}$, we are at the edge of the classical "Zone of Silence" in which standard ray-tracing fails to predict infrasound (e.g. Negraru et al., 2010). Many events from other sources have also been recorded seismically and acoustically. Gibbons and Ringdal (2010) study explosions at an unknown site on the Kola Peninsula. These explosions had the advantage of being carried out all year round over several years, allowing the investigation of seasonal effects along different paths. ARCES and LYC (to the West and South West respectively) received signals for almost all summer events and for almost no winter events. To the South, APAI received signals all year round. Such considerations are important if using infrasound as a monitoring technology for explosions or natural hazards in specific locations. It was also pointed out that, while the seismic signals generated by these explosions were detectable up to approximately $300 \mathrm{~km}$, the infrasound signals propagated many hundreds of kilometers, given a favorable stratospheric waveguide.

The treaty coordinates for the planned I37NO array were at Karasjok in northern Norway - essentially co-located with ARCES. Despite successful site tests in 1998, protests from local authorities meant that construction had not even started as of 2007. Early in 2008, an experimental microbarograph sub-array (ARCI) was deployed within ARCES to record infrasound signals free of the filtering effect of the infrasound to ground motion conversion. Since planning authorities would not permit any aboveground, permanent, noise-reduction system, the only alternative was porous hoses laid loosely over 
the ground. Despite highly varying noise levels, this experimental infrasound array rapidly revealed a surprisingly diverse range of signals from seismo-acoustic sources. Many "new" sources of seismoacoustic events were discovered that generated infrasound signals too weak to be observed on the seismic traces: the Kittilä gold mine (Suurikuusikko), the Sydvaranger ore mine (Kirkenes) which reopened in 2009, and the Kevitsa mine which opened in 2012. Evers and Schweitzer (2011) processed over a year of $\mathrm{ARCl}$ data in both high and low frequencies, and found high frequency signals from many known industrial and military sources consistent with the seasonal expectations for the stratospheric waveguide. Table 1 summarizes most of the region's seismo-acoustic sources that generate infrasound signals recorded on the array stations in the region, summarized in Figure 4. In June 2009, the CTBTO (Comprehensive Nuclear-Test-Ban Treaty Organization) Preparatory Commission approved a coordinate change for I37NO to Bardufoss, approximately $275 \mathrm{~km}$ South-byWest of Karasjok. The new location is in low-lying pine forest and shielded from wind by topography, providing an ideal natural low-noise site. The array was completed in 2013 with 10 sites deployed over an aperture slightly larger than 1 kilometer. Each of the 10 sites is equipped with an $18 \times 18$ meter wind noise reduction filter. Details of the installation are provided by Fyen et al. (2014). Early in 2013, a 9-element array equipped with Hyperion IFS-3112 infrasound sensors (NRSI) was constructed co-located with seismometers of the 3-component NORES seismic array in pine forest in the south of Norway. Figure 4 indicates the time-spans of sensors in the region and, for any given time, indicates the amount of data available. It should also be noted that the Norwegian, Swedish, and Finnish seismic networks have expanded significantly in this time, providing an ever denser recording framework to characterize the seismic and infrasonic wavefields. Without providing details of the incremental changes to the different networks, we point in particular to the LAPNET deployment in northern Finland between 2007 and 2009. LAPNET had a spatial separation comparable to that of the Transportable Array component of the IRIS/NSF-funded U.S. array which 
has provided unprecedented spatial sampling of the infrasonic wavefield from explosive sources in the United States (e.g. Hedlin and Walker, 2013). 
Table 1: Sites of known repeating seismo-acoustic events in the region.

\begin{tabular}{|lllll|}
\hline Site & Lat & Lon & $\begin{array}{l}\text { Approximate } \\
\text { number of events }\end{array}$ & Notes \\
\hline Halkavarre & 69.90 & 25.22 & $\sim 15-20$ & Norwegian military \\
\hline Hukkakero & 67.94 & 25.84 & $\sim 500$ & $\begin{array}{l}\text { Finnish military. Yield 20000 kg. } \\
\text { (Gibbons et al., 2007: Aug-Sept) }\end{array}$ \\
\hline Novaya Titovka & 69.53 & 31.93 & $\sim 700$ & $\begin{array}{l}\text { Russian military. Yield unknown. } \\
\text { (Gibbons and Ringdal, 2010: all year) }\end{array}$ \\
\hline $\begin{array}{l}\text { Kola Peninsula } \\
\text { (Near Novaya } \\
\text { Titovka) }\end{array}$ & 69.57 & 32.83 & $\sim 6$ & Unknown source. East of above source. \\
\hline $\begin{array}{l}\text { Kirkenes ore } \\
\text { mine }\end{array}$ & 69.59 & 29.96 & $\sim 100$ & $\begin{array}{l}\text { (Sydvaranger mine.) } \\
\text { Restarted production in 2009. }\end{array}$ \\
\hline $\begin{array}{l}\text { Suurikuusikko } \\
\text { Kevitsa quarry }\end{array}$ & 67.90 & 25.39 & 500 & $\begin{array}{l}\text { Kittilä gold mine. } \\
\text { (Since 2006). }\end{array}$ \\
\hline $\begin{array}{l}\text { Laiva Gold Mine } \\
\text { (Raahe, Finland) }\end{array}$ & 64.54 & 24.58 & Many hundreds & Copper and nickel quarry: from 2012. \\
\hline Aitik quarry & 67.06 & 20.90 & Many hundreds & Large ripple-fired events \\
\hline Kovdor & 67.56 & 30.43 & Many hundreds & $\begin{array}{l}\text { Large ripple-fired events } \\
\text { (See Gibbons et al., 2005) }\end{array}$ \\
\hline Khibiny massif & 67.67 & 33.73 & Many hundreds & Several mines within a few km. \\
\hline $\begin{array}{l}\text { Olenegorsk } \\
\text { Zapoljarni }\end{array}$ & 68.10 & 33.10 & Many hundreds & Several mines within a few km. \\
\hline Kostomuksha & 64.73 & 30.70 & Many hundreds & Two pits with small separation. \\
\hline
\end{tabular}




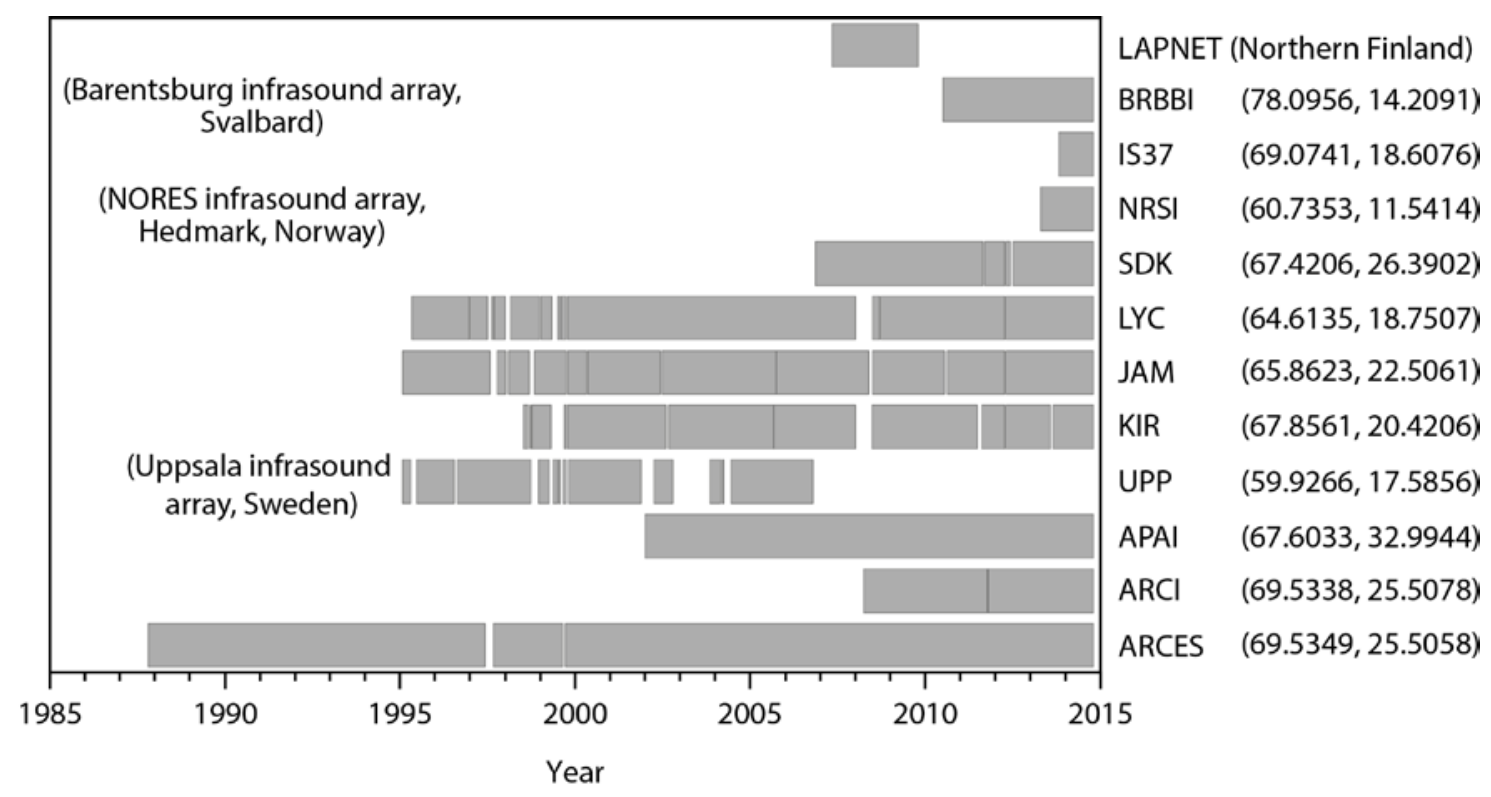

Figure 4 Time-spans of archived digital seismic/infrasonic data recording. All stations as displayed in Figure 3 except where labelled. 


\section{ARRAY PROCESSING CONSIDERATIONS}

Array processing is fundamental to interpreting infrasound signals. Signals on individual sensors with very high SNR may be understood given a very obvious source, or interpreted in the context of signals observed across a large network. However, more usually, a low-SNR signal can only be separated from the background noise given a significant correlation with the waveforms on neighboring sensors with appropriate time delays. Progressive Multi-channel Cross-Correlation (PMCC, Cansi, 1995) has become the workhorse of infrasound processing at the IDC. Incoming data channels of an array are correlated against each other and detections declared when the set of correlation-determined time-delays on groups of 3 sensors is consistent with a plausible wavefront. "Progressive" refers to the fact that a meaningful estimate of propagation parameters on one subset of sensors will extend the correlation procedure to increasingly many sensors over which the parameter estimates are consolidated. In the newest PMCC implementations (Brachet et al., 2010) the correlation is performed in multiple frequency bands and significant detections are identified by consistency of coherence and parameter estimates over many frequencies and over an extended time-window. 


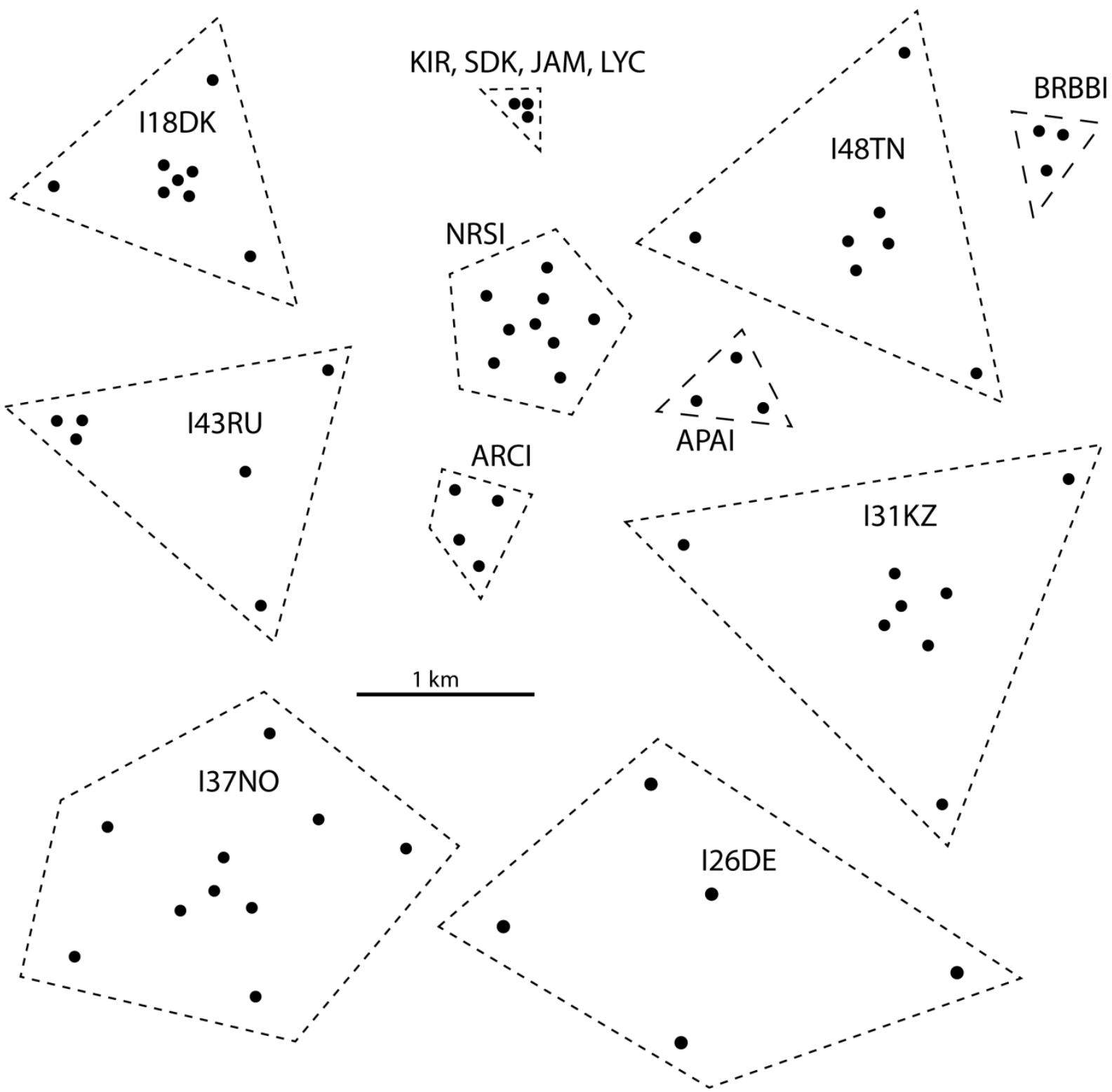

Figure 5 Infrasound array geometries drawn to a common scale.

PMCC provides robust detection lists and superb visualization of the evolution of coherent energy with time, but does not provide a means to examine the slowness resolution. The detection statistic of Brown et al. (2002) performs the cross-correlations in the same manner as PMCC but then scans the entire slowness space for significant arrivals. (We note that similar approaches have been considered for seismic array analysis, e.g. Frankel et al., 1991.) The visualization of the array response to a given wavefront (e.g. Brown et al., 2014) is necessary for the operator to understand the significance and accuracy of the output. Slowness scans may indicate significant sidelobes (aliased energy), low resolution, or multiple wavefronts. Figure 5 displays the geometries of some of the 
arrays mapped out in Figure 2 . The larger and sparser arrays will have better resolution for lower frequencies but may be incoherent at high frequencies, for which the small aperture arrays are more effective.

Prior to NRSI and I37NO, all infrasound detection in the region was performed either on a microbarograph or microphone array (with only 3 or 4 sensors) or on a seismometer array with many sensors $(9,16$, or 25$)$. A 3-sensor array is a minimal configuration with no redundancy. A signal must be well observed on all sensors to be able to determine apparent velocity and backazimuth, and we are vulnerable to the loss of a single sensor. Figure 6 illustrates slowness estimation for an infrasound signal using the broadband frequency-wavenumber (f-k) analysis (Kværna and Doornbos, 1986) typically applied on seismic arrays. We demonstrate that the sidelobes can be reduced by performing the $f-k$ analysis on cross-correlation functions rather than the waveforms themselves. The left panel of Figure 6 displays 20 seconds of data from the original $3 \mathrm{ARCl}$ microbarographs. The signal is from one of the events discussed by Gibbons and Ringdal (2010), a presumed near-surface Titovka explosion at approximately $250 \mathrm{~km}$. The $\mathrm{f}-\mathrm{k}$ spectrum shows significant sidelobes due to the dominance of energy at the lower end of this frequency range. (Shifting one of the traces by one cycle at the dominant frequency would not reduce the beam gain greatly, hence the strong sidelobe). The right hand panel of Figure 6 shows all the correlations between the 3 data traces. In a PMCC-type implementation, the time-delays between the maxima would be measured and the propagation parameters estimated accordingly. By assigning the co-array coordinates to the cross-correlation functions, and performing the same broadband $f-k$ analysis, we obtain a very similar slowness estimate but with substantially reduced sidelobes. The correlation has concentrated the coherent energy over the long time window into a single time instance, with the shape and ringing of the correlation function determined by the time-bandwidth product of the signals. Reduced sidelobes in the time-domain cross-correlation functions give reduced sidelobes in the f-k spectrum. The broadband $\mathrm{f}-\mathrm{k}$ analysis with the cross-correlation functions is unnecessary; a simple stacking with 
appropriate time-delays (c.f. Frankel et al., 1991; Brown, 2002) will also provide a robust detection statistic.

a)
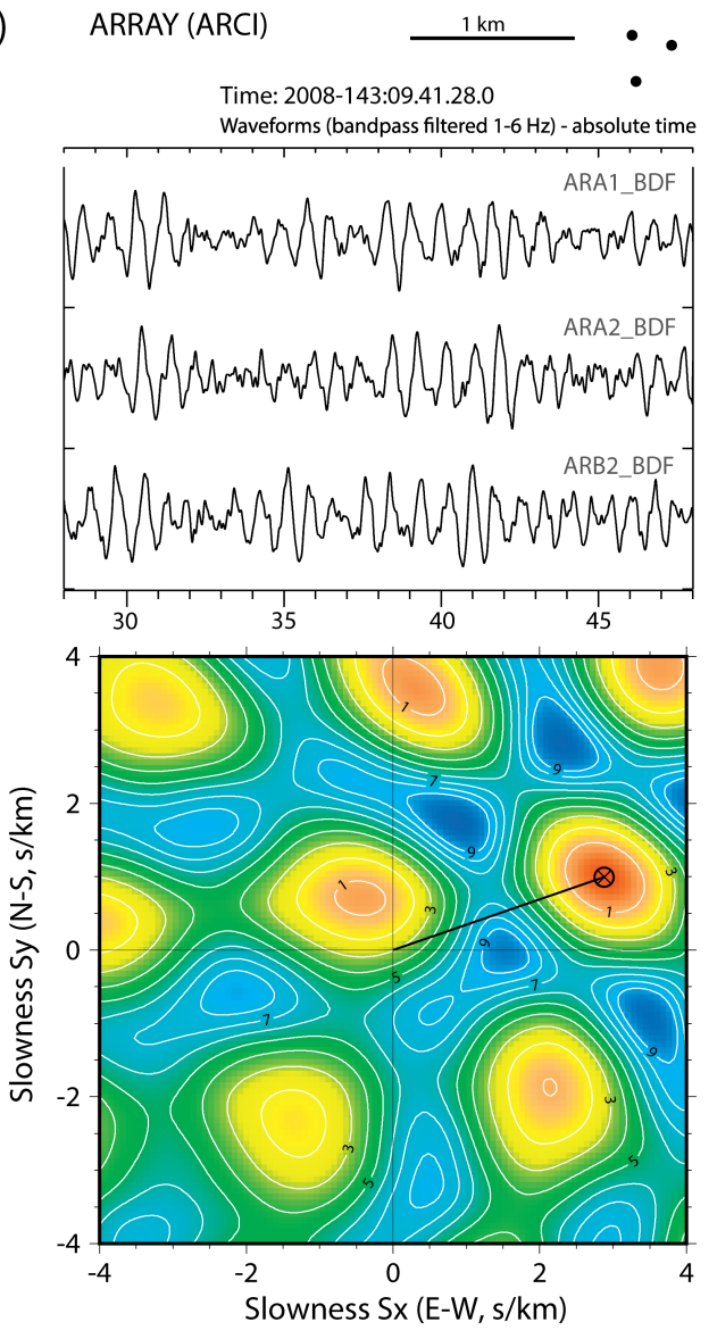

Frequency band: $1.00-6.00 \mathrm{~Hz}$

Vel: $0.33 \mathrm{~km} / \mathrm{s}$, Azi: $70.9 \mathrm{deg}$

Pwr: 0.92, Time: 2008-143:09.41.28.0 + $20.0 \mathrm{~s}$ b) $\quad \bullet \quad 1 \mathrm{~km} \quad$ CO-ARRAY

-

Cross-correlation traces between waveforms - relative time (s)
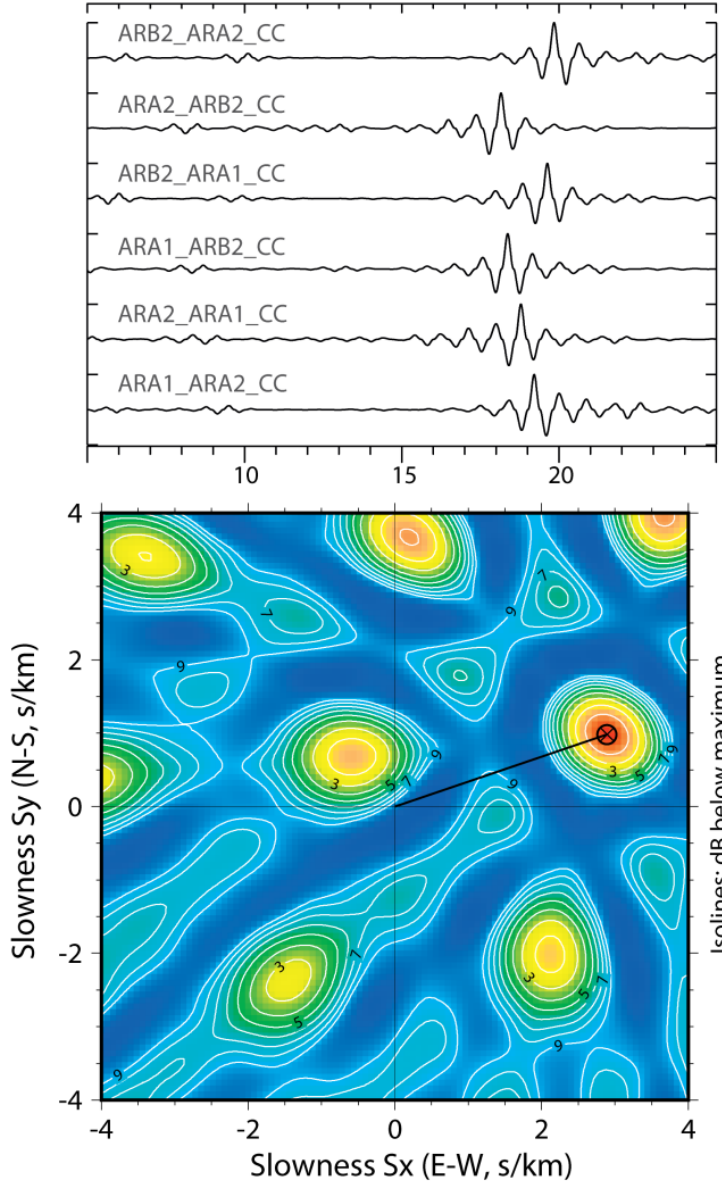

Frequency band: $1.00-6.00 \mathrm{~Hz}$

Vel: $0.33 \mathrm{~km} / \mathrm{s}$, Azi: $71.2 \mathrm{deg}$

Pwr: 0.96, Time: 2008-143:09.41.14.0 + 20.0 s

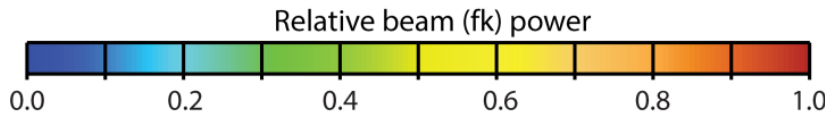

Figure 6. Slowness estimation using broadband $f-k$ analysis for an infrasound signal on the ARCI array. The frequency-wavenumber spectra are evaluated for many narrow frequency bands between 1 and $6 \mathrm{~Hz}$ and summed incoherently (Kværna and Doornbos, 1986). On the left, the f-k analysis is performed on the bandpass filtered waveforms themselves. On the right, the f-k analysis is performed on the cross-correlation functions and this demonstrably reduces the relative amplitudes of the sidelobes in this example. 
A wealth of information about the infrasonic wavefield has been gleaned from acoustic signals on the seismic data. The amplitudes can be significant; for many Hukkakero and Titovka explosions, the acoustic phase amplitude exceeds the seismic wavetrain amplitude greatly. However, more usually, the SNR is low and an acoustic signal is only detected by identifying significant coherence between channels with appropriate time-shifts. Observing infrasound on seismic sensors can also give the impression of high frequency dominance. This is likely to be a combination of a frequency-dependent acoustic-seismic coupling (e.g. Langston, 2004; Edwards et al., 2009) and the fact that the background seismic noise at the lower frequencies is very much stronger. Figure 7 shows a typical example of such a signal on the FINES seismic array. Not only is no acoustic signal visible in the filtered waveforms (Figure 7a), the individual cross-correlation traces (Figure 7b) show no significant infrasound-compatible local maxima (therefore likely to cause difficulties for a PMCC-type algorithm). However, stacking the 210 channel-pair correlations according to time-delays specified by the coordinates in slowness space results in 2 peaks of comparable strength. One, propagating with higher apparent velocity, results from the seismic noise wavefield. The other, with far lower apparent velocity, is consistent with an infrasound arrival from a reported accidental explosion near St. Petersburg in Russia. 
a)

Short period vertical seismic traces from FINES array

3 of 15 channels displayed (filter $2-5 \mathrm{~Hz}$ )

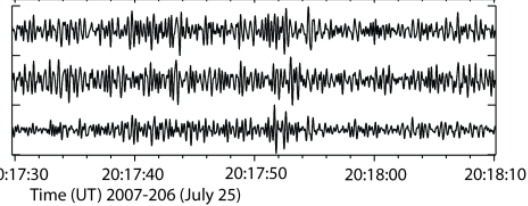

b)

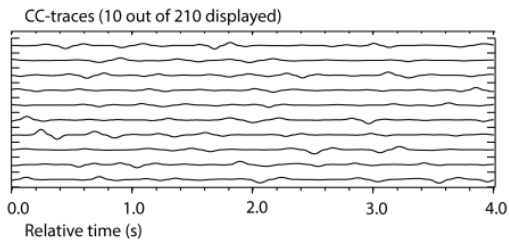

c)

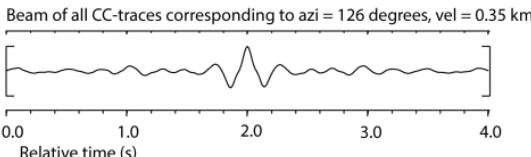

d)

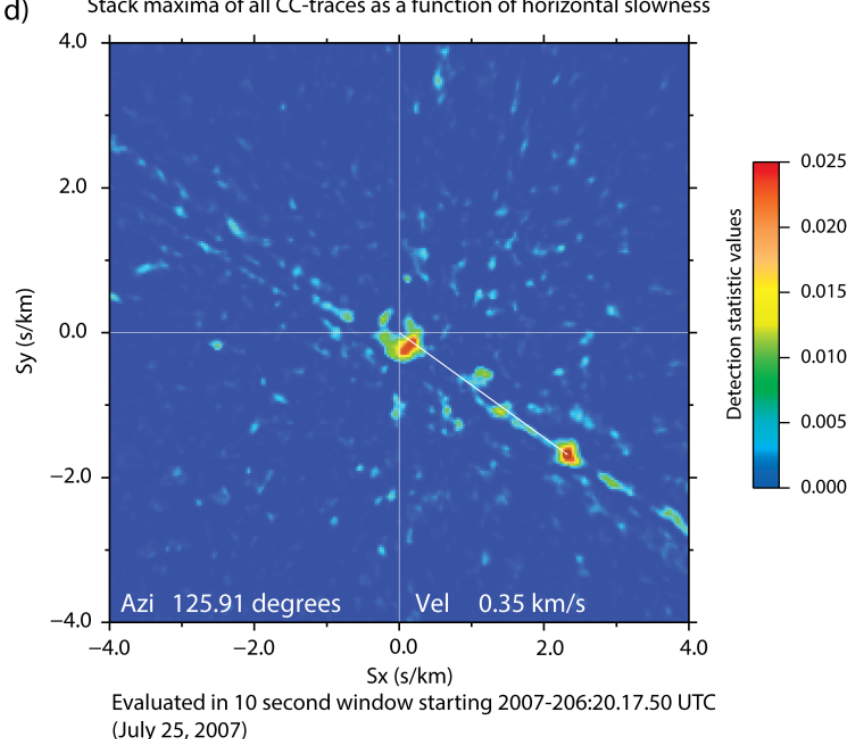

Figure 7 Detection and estimation of a weak acoustic signal (a) on the FINES seismic array. No significant local maxima are found on the vast majority of individual cross-correlation traces (b) and no detection or estimation can be performed using direct delay-time measurements. A crosscorrelation stack (c.f. Brown et al., 2002) provides peaks for two distinct slownesses, one due to seismic noise and the other for an acoustic signal consistent with a gas pipe explosion in St. Petersburg. Each point in the slowness grid (d) represents a set of time-shifts by which the single CC-channels (b) can be delayed. In (c), the CC-trace stack with time-delays corresponding to the acoustic signal is displayed, showing a clear local maximum.

While cross-correlation stacking estimates have proven highly effective on the region's arrays, it should be noted that there are numerous array processing techniques which may be more effective in some circumstances. The F-statistic detectors (Blandford, 1974) have been undergoing a renaissance in infrasound (e.g. Arrowsmith et al., 2009) and, with a likely increasing emphasis on multivariate detection algorithms (e.g. Arrowsmith and Taylor, 2013), it is sensible to run multiple detectors (PMCC, Correlation Trace Stacking, F-statistic and adaptive F-statistic) in parallel to consolidate safe and significant detections and minimize the likelihood of missing signals of potential interest. 


\section{OBSERVATIONS FROM REPEATING SEISMO-ACOUSTIC SOURCES}

Among many known repeating seismo-acoustic sources in the region, the Hukkakero ammunition destruction explosions remain of great interest due to the large size of the events and the event-toevent repeatability of the source. For the 2008 Hukkakero sequence, microbarographs were colocated with short-period seismometers at ARCES for the first time and a record number of 36 explosions were carried out. For each event, Figure 8 shows almost 20 minutes of filtered seismic data from the ARA1 vertical seismometer alongside the corresponding segment from the co-located microbarograph. Within the first minute after the explosions, the seismic $\mathrm{P}$ and $\mathrm{S}$ phases have arrived. The vertical scaling is identical for each event, confirming that the event-to-event variability of the seismic wavetrain amplitude is unlikely to be significant. To separate the acoustic and seismic energy in Figure 8, we color the background with an intensity proportional to the detection statistic at times consistent with an acoustic wavefront from Hukkakero. A number of events (e.g. 14, 16) show no red shading for the seismometer traces and unrelated seismic signals are seen in the timewindows where we anticipate the acoustic arrivals. The traces are aligned accurately using the seismic signals and the moveout of the acoustic phase in the plot is a direct measure of celerity (the distance over ground divided by the traveltime). A small number of events (e.g. 5, 13, and 29) show acoustic energy at around 500 seconds (celerity approximately $0.36 \mathrm{~km} / \mathrm{s}$ ) whereas most events result in acoustic energy between 600 and 650 seconds (celerity approximately $0.28 \mathrm{~km} / \mathrm{s}$ ). The faster arrivals are likely tropospheric phases and the slower arrivals are likely stratospheric phases.

The seismic signals are not evident in Figure 8 (b), and coherence analysis on the microbarographs indicates acoustic arrivals even for those events missing infrasound on the seismic traces. The uniform scaling of the microbarograph traces shows the significant day-to-day variability of the infrasonic background noise. For most events, the infrasound SNR is unsurprisingly higher on the microbarographs than on the seismometers and the temporal forms of the acoustic phases are more easily compared. Significantly, the infrasound signals on microbarographs indicate longer signal durations. Some signals lasting around 20 seconds on the seismic data last well over a minute on the 
microbarograph data. We conclude that, while the seismic sensors have served us well in confirming the presence of the infrasound, the full picture of the acoustic wavefield at this distance may be qualitatively different from the "tip of the iceberg" image provided on the seismometers with a significant part of the converted infrasonic wavetrain hidden below the seismic noise level.

Another surprising observation for the 2008 Hukkakero explosions was the detection of acoustic phases at approximately 900 seconds (celerity approximately $0.2 \mathrm{~km} / \mathrm{s}$ ) for 11 of 36 events. Close inspection of 3 of 36 events showed evidence for these arrivals on the seismic waveforms. The lowermost panels of Figure 8 display slowness grids for the two indicated time intervals. The signal at around 625 seconds has an apparent velocity of approximately $0.34 \mathrm{~km} / \mathrm{s}$ whereas the signal at around 925 seconds has an apparent velocity of $0.57 \mathrm{~km} / \mathrm{s}$. Given an essentially identical local air sound-speed at these two times, we infer a steeper angle of incidence for the later phase and a likely higher return altitude. The low celerity, lower frequency signal, and greater angle of incidence are indicative of thermospheric phases (e.g. Mutschlecner and Whitaker, 1999; Whitaker and Mutschlecner, 2008). Given that the effective velocity in the thermosphere always exceeds the effective velocity at ground-level, thermospheric phases are always predicted. However, they are observed relatively infrequently due to the relative sparsity of the atmosphere at these altitudes which attenuates the higher frequencies strongly (Sutherland and Bass, 2004). 

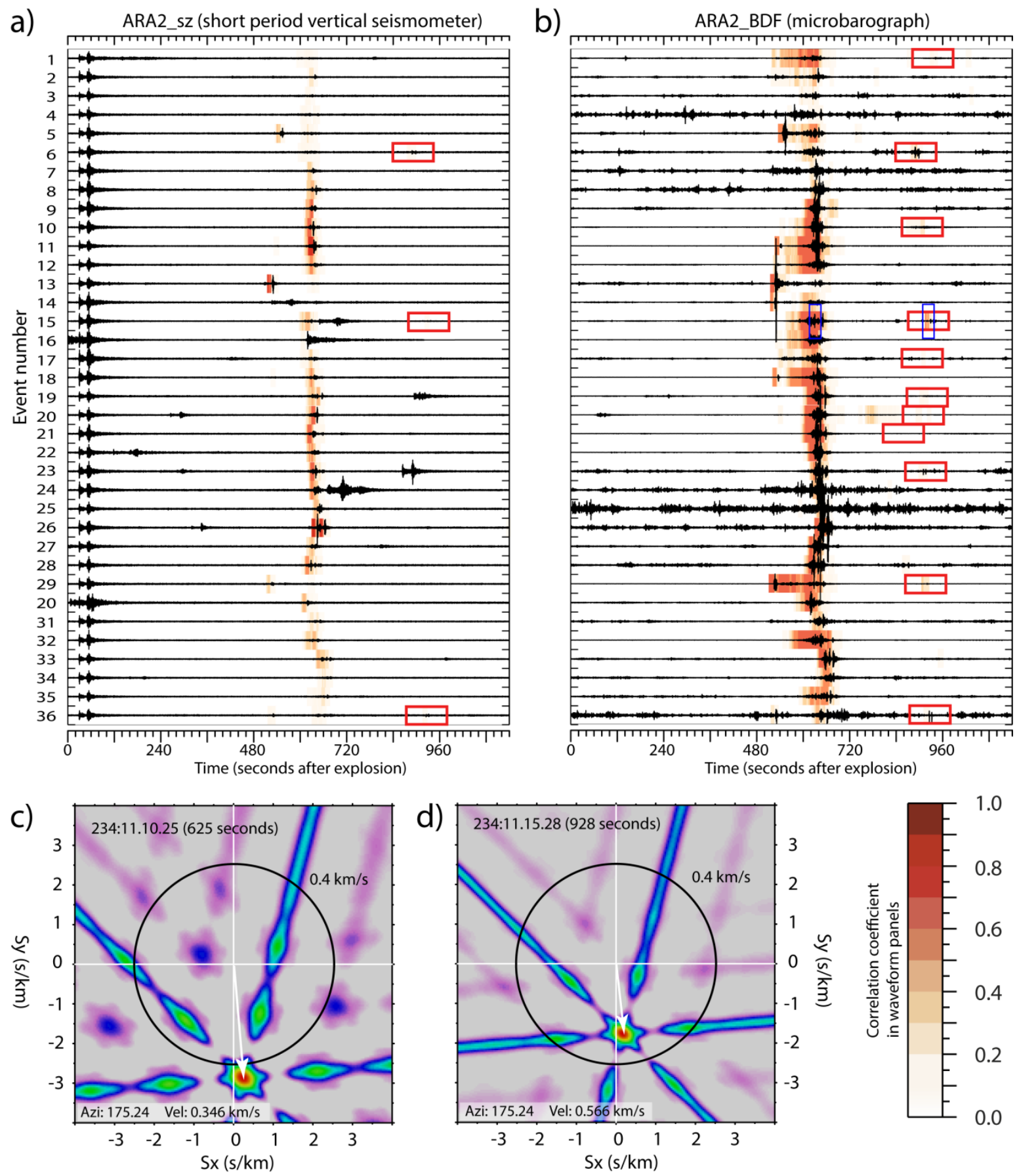

Figure 8 Seismometer (a) and co-located microbarograph (b) data at ARCES for each of 36 explosions at Hukkakero between August 13 and September 11, 2008, filtered 2-7 Hz. Behind the waveforms, the color intensity indicates the correlation stack maximum (c.f. Brown et al., 2002) for overlapping 10-second windows with slowness consistent with an acoustic phase from the explosion site. The red boxes enclose those segments where the apparent velocity exceeds 0.4 $\mathrm{km} / \mathrm{s}$. The slowness scans (c) and (d) are taken for the $3 \mathrm{ARCl}$ microbarographs for the timeintervals marked with blue boxes for event 15 at 11:00 UT on August 21, 2008. 
The 2014 Hukkakero sequence was the first to be recorded by IS37 (distance approximately $320 \mathrm{~km}$ ). 15 explosions took place between August $22^{\text {nd }}$ and September $3^{\text {rd }}$. The first 12 events were consistent with the yield of previous explosions; the final three were very small events (magnitude below 1 ) with seismic signals only detectable at ARCES with the correlation detector. (Their presence was also confirmed using closer seismic stations.) Figure 9 displays filtered waveforms from IS37 for each of these 15 explosions, aligned using the seismically inferred origin times. The ARCES seismic traces are superimposed at the start of the IS37 microbarograph traces. All of the larger explosions resulted in very high SNR acoustic signals after 18 minutes (celerity $0.296 \mathrm{~km} / \mathrm{s}$ ) and the apparent velocity for all of the acoustic arrivals between 18 and 20 minutes is quite constant at around $0.34 \mathrm{~km} / \mathrm{s}$, indicating a comparable angle of incidence. Between 20 and 22 minutes, lower frequency phases are observed with generally higher apparent velocities (angles of incidence). These properties are consistent with thermospheric phases (Whitaker and Mutschlecner, 2008) and the differing apparent velocities for these later phases indicate returns from different altitudes. It is noted that short duration infrasound was detected at IS37 for all 3 of the final low-yield explosions. 


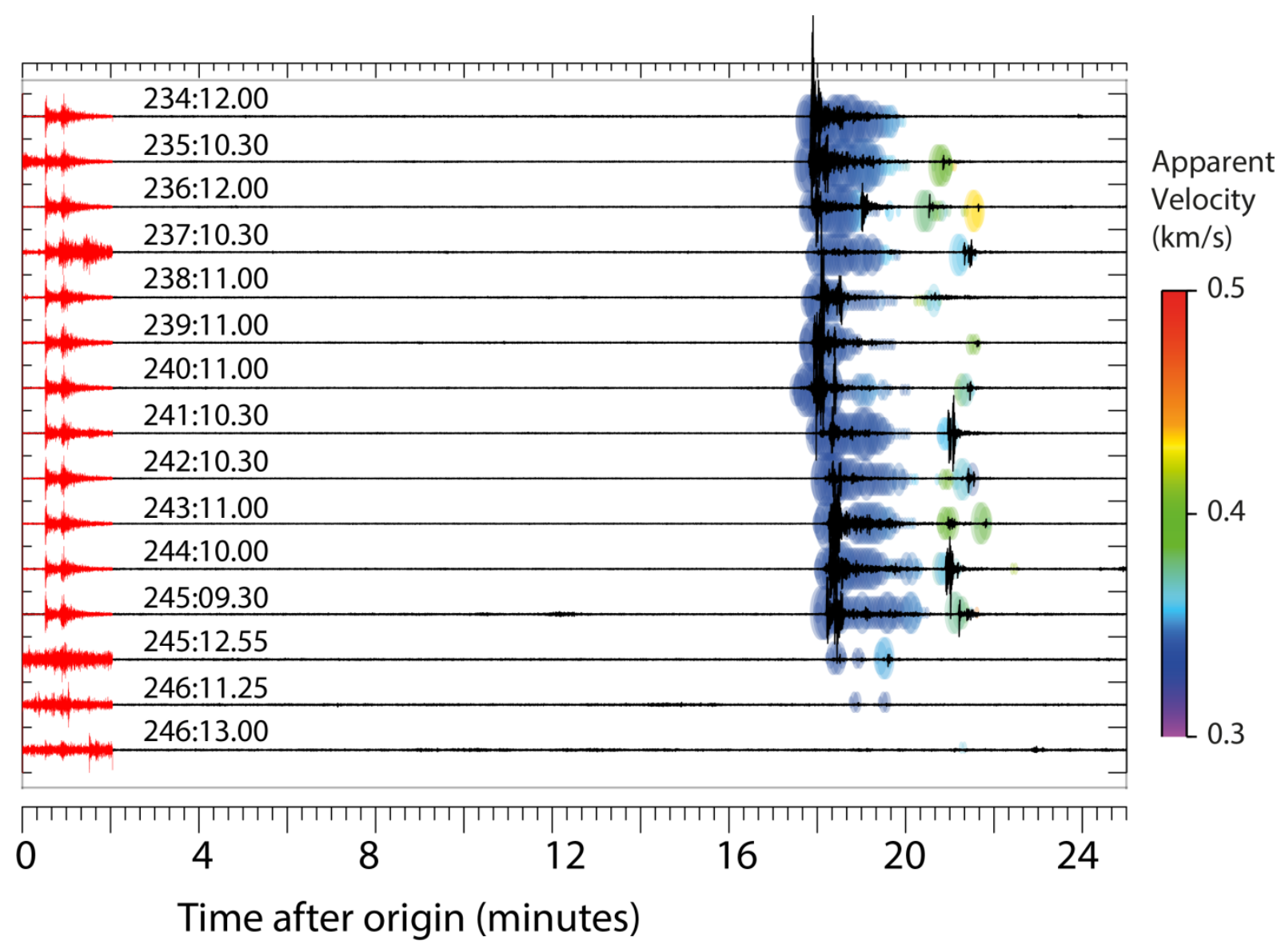

Figure 9 Microbarograph data (1-4 Hz) at the IS37 central site (black) and seismic data (4-16 Hz) at the ARCES central site (red) for 15 Hukkakero events in 2014. The symbols behind the waveforms indicate the apparent velocity and are sized proportional to the cross-correlation stack peak, provided consistency with a relevant infrasound signal. The cross-correlation values range between over 0.9 for the strongest signals to around 0.1 for signals right at the noise level. The first 12 events have a presumed explosive yield of approximately 20T, the final 3 are far smaller. The origin time is given to the nearest minute in the format ddd:hh. $\mathrm{mm}$ where ddd, hh, and $\mathrm{mm}$ are the day of year, the hour, and minute respectively. All waveforms are aligned using the seismic signals. 


\section{DISCUSSION}

The European Arctic has become an exceptional observatory for seismo-acoustic studies and investigations into infrasound propagation. A relatively dense network of sensor arrays with a long history of digital recording, combined with many repeating anthropogenic sources of infrasound, has resulted in an unprecedented temporal sampling of the regional infrasonic wavefield. The permanent seismic arrays and networks allow the times and locations of explosions to be constrained accurately. This facilitates a tomographic approach to exploiting infrasound arrivals over the sensor network to assess the fidelity of atmospheric models. Similar procedures are being followed elsewhere, e.g. Korea (Che et al., 2011) and the U.S. (Nippress et al., 2014), to examine the variability of the recorded infrasonic wavefield and the consequences for infrasonic event detection and location capability. In the same way that seismic tomography is performed regionally and locally to illuminate structure at the respective spatial scales, atmospheric tomography needs to be performed as broadly as possible to understand the temporal and spatial variability of the atmosphere. Examining time-series of the type here will allow us to build empirical distributions of anticipated infrasound observations which can be applied to assess network capability, both for general and site-specific monitoring.

The observational network has expanded significantly in recent years and additional upgrades and new deployments are likely to improve the network capability substantially. The LAPNET seismic deployment in northern Finland comprised stations with spacings of between 50 and $70 \mathrm{~km}$ and many instruments recorded explosions at Hukkakero and other sources over the two years of the deployment. Figure 10 shows very high SNR acoustic signals from Hukkakero blasts converted into seismic motion on the closest of the LAPNET sensors at a distance of $25 \mathrm{~km}$. Also shown are converted infrasound signals from mining explosions at the Suurikuusikko gold mine, at lower amplitude but showing a comparable variability in celerity and signal duration. The permanent seismic networks in the region are also expanding as the limitations of data transmission and storage diminish, and as society's needs to monitor seismicity on ever smaller scales increases. The benefits 
of augmenting the USArray Transportable Array seismic stations with microbarographs has been demonstrated (e.g. Edwards et al., 2014) and dense deployments of single-site microbarographs colocated with existing seismic stations could provide a coordinated picture of acoustic wave propagation for larger sources. Reverse Time Migration (RTM), scanning time and location for sources consistent with network observations is a promising method for characterizing infrasound sources over a sparse network (e.g. Hedlin and Walker, 2013). Empirical distributions for observation probability versus celerity (Morton and Arrowsmith, 2014) will be crucial in obtaining realistic location uncertainty estimates both in RTM-type procedures and in probabilistic methods for acoustic event location (Modrak et al., 2014).

Similarly, augmenting existing infrasound arrays with one or more seismic sensors may help to identify the sources of signals observed on microphone or microbarograph arrays. A clear seismic signal may provide an immediate identification of an infrasound source, or may provide far better location and origin-time constraints than infrasound data alone can provide. Conversely, the absence of a seismic signal may immediately rule out industrial or military sources on the ground and indicate an airborne source. Ground Truth provides a benchmark with which to evaluate network detection and location capability, in addition to validating models of atmospheric specification and infrasound propagation. Seismo-acoustic data processing on regional scales has intrinsic value both for atmospheric research and for a characterization of anthropogenic and potentially hazardous natural events. However, a comprehensive characterization of regional infrasound is also likely to improve the picture of global monitoring capability. We have demonstrated the benefits of sharing data both between different technologies and across national boundaries. Seismic signals in one country may identify or explain an apparent acoustic event in another, and an infrasound detection in one nation may discriminate the nature of a seismic event recorded elsewhere. 
a)

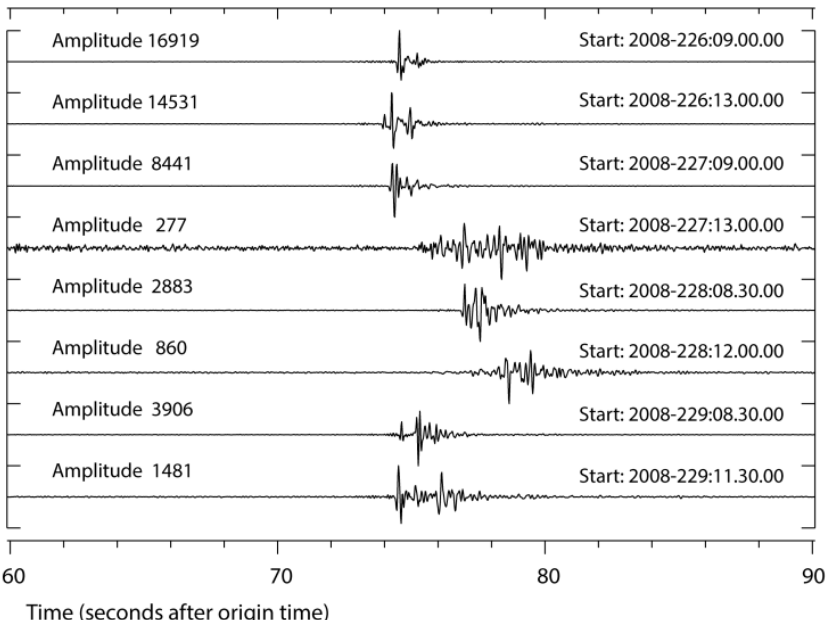
LP62_BHZ - bandpass filter 2-12 Hz

(25 km from explosion site at Hukkakero)
Time (seconds after origin time)

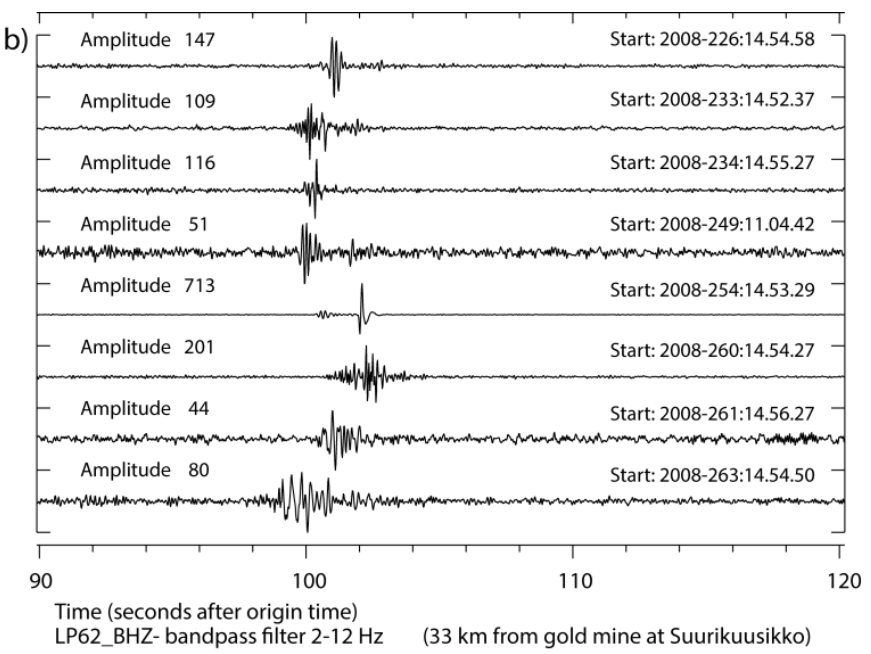

Figure 10 Waveforms from the BHZ channel of the LP62 station of the LAPNET deployment following 8 explosions at Hukkakero (a: distance $25 \mathrm{~km}$ ) and 8 explosions at the Suurikuusikko gold mine (b: distance $33 \mathrm{~km}$ ). 


\section{ACKNOWLEDGEMENTS}

Maps generated using GMT (Wessel and Smith, 1995).

The LAPNET/POLENET data was funded as part of the 2007-2008 International Polar Year Program.

This project is partly funded by the European Union under the $7^{\text {th }}$ Framework Programme as part of the ARISE project. 


\section{DATA AND RESOURCES}

Infrasound data from the IS37 array, and data from all seismic stations operated by NORSAR, can be obtained freely via AutoDRM request at http://www.norsardata.no/NDC/data/autodrm.html (last accessed February 2015).

Data from other infrasound stations operated by NORSAR can be obtained by individual agreement: please contact info@norsar.no.

One-day helicorder plot image files from all NORSAR stations can be viewed on http://www.norsardata.no/NDC/data/ (last accessed February 2015).

Pre-processed infrasound data from the Swedish-Finnish Infrasound Network (SFIN) is freely available at http://www.umea.irf.se/maps and the original time series can be obtained after an individual request at http://www.umea.irf.se/iltserie/ (last accessed February 2015).

Data from stations operated by the Kola Regional Seismological Center can be obtained by individual agreement: please contact asmingve@mail.ru. 


\section{REFERENCES}

Arrowsmith, S. J., R. Whitaker, C. Katz, and C. Hayward (2009). The F-Detector Revisited: An Improved Strategy for Signal Detection at Seismic and Infrasound Arrays, Bulletin of the Seismological Society of America 99, 449-453, doi:10.1785/0120080180

Arrowsmith, S. J., and S. R. Taylor (2013). Multivariate acoustic detection of small explosions using Fisher's combined probability test, Journal of the Acoustical Society of America 133, EL168EL173, doi:10.1121/1.4789871

Asming, V. E., S. V. Baranov, Yu Vinogradov, and A. I. Voronin (2013). Seismic and infrasonic monitoring on the Spitsbergen archipelago, Seismic Instruments 49, 209-218, doi:10.3103/s074792391303002x

Blandford, R. (1974). An automatic event detector at the Tonto Forest Seismic Observatory, Geophysics 39, 633-643, doi:10.1190/1.1440453

Brachet, N., D. Brown, R. Le Bras, Y. Cansi, P. Mialle, and J. Coyne (2010). Monitoring the Earth's Atmosphere with the Global IMS Infrasound Network, Chapter 3 in "Infrasound Monitoring for Atmospheric Studies", Le Pichon, A., Blanc, E., and Hauchecorne, A. (eds.), Springer Science and Business Media, B. V, 77-118. doi:10.1007/978-1-4020-9508-5 3

Brown, D. J., C. N. Katz, R. Le Bras, M. P. Flanagan, J. Wang, and A. K. Gault (2002). Infrasonic Signal Detection and Source Location at the Prototype International Data Centre, Pure and Applied Geophysics, 159, 1081-1125, doi:10.1007/s00024-002-8674-2

Brown, D. J., C. A. L. Szuberla, D. McCormack, and P. Mialle (2014). The Influence of Spatial Filters on Infrasound Array Responses, Pure and Applied Geophysics 171, 575-585, doi:10.1007/s00024$\underline{012-0586-1}$

Cansi, Y. (1995). An automatic seismic event processing for detection and location: The P.M.C.C. method, Geophysical Research Letters 22, 1021-1024, doi:10.1029/95gl00468

Ceranna, L., A. Le Pichon, D. N. Green, and P. Mialle (2009). The Buncefield explosion: a benchmark for infrasound analysis across Central Europe, Geophysical Journal International, 177, 491508, doi:10.1111/j.1365-246x.2008.03998.x

Che, II-Young, B. W. Stump, and Hee-II Lee (2011). Experimental characterization of seasonal variations in infrasonic traveltimes on the Korean Peninsula with implications for infrasound event location, Geophysical Journal International 185, 190-200, doi:10.1111/j.1365246x.2011.04948.x

Christie, D. R., and P. Campus (2010). The IMS Infrasound Network: Design and Establishment of Infrasound Stations, Chapter 2 in "Infrasound Monitoring for Atmospheric Studies", Le Pichon, A., Blanc, E., and Hauchecorne, A. (eds.), Springer Science and Business Media, B. V, 29-75. doi:10.1007/978-1-4020-9508-5 2 
Dahlman, O., S. Mykkeltveit, and H. Haak (2009). Nuclear Test Ban: Converting Political Visions to Reality, Springer Science+Business Media B.V, Dordrecht, The Netherlands ISBN: 978-1-40206883-6 (Print) 978-1-4020-6885-0 (Online) 10.1007/978-1-4020-6885-0

Dahlman, O., J. Mackby, S. Mykkeltveit, and H. Haak (2011). Detect and Deter: Can Countries Verify the Nuclear Test Ban? Springer Science+Business Media B.V, Dordrecht, The Netherlands. ISBN: 978-94-007-1675-9 (Print) 978-94-007-1676-6 (Online) doi:10.1007/978-94-007-1676-6

Edwards, W. N., P. G. Brown, and D. W. Eaton (2009), Frequency-Dependent Acoustic-Seismic Coupling of Meteor Shock Waves, Bulletin of the Seismological Society of America 99, 30553066, doi:10.1785/0120080226

Edwards, W. N., C. D. de Groot-Hedlin, and M. A. H. Hedlin (2014). Forensic Investigation of a Probable Meteor Sighting Using USArray Acoustic Data, Seismological Research Letters 85, 1012-1018, doi:10.1785/0220140056

Evers, L. G. (2008). The inaudible symphony: on the detection and source identification of atmospheric infrasound, Ph.D. thesis, TU Delft, Delft, ISBN 978-90-71382-55-0, 170 pp. http://www.knmi.nl/publications/fulltexts/thesisevers medium.pdf

Evers, L. G., and H. W. Haak (2005). The detectability of infrasound in The Netherlands from the Italian volcano Mt. Etna, Journal of Atmospheric and Solar-Terrestrial Physics 67, 259-268, doi:10.1016/j.jastp.2004.09.002

Evers, L. G., and H. W. Haak (2009). The Characteristics of Infrasound, its Propagation and Some Early History, Chapter 1 in "Infrasound Monitoring for Atmospheric Studies", Le Pichon, A., Blanc, E., and Hauchecorne, A. (eds.), Springer Science and Business Media, B. V, 3-27. doi:10.1007/978-1-4020-9508-5 1

Evers, L., and J. Schweitzer (2011). A climatology of infrasound detections in northern Norway at the experimental ARCl array, Journal of Seismology 15, 473-486, doi:10.1007/s10950-011-9237-8

Evers, L. G., L. Ceranna, H. W. Haak, A. Le Pichon, and R. W. Whitaker (2007). A Seismoacoustic Analysis of the Gas-Pipeline Explosion near Ghislenghien in Belgium, Bulletin of the Seismological Society of America, 97, 417-425, doi:10.1785/0120060061

Fee, D. and R. S. Matoza (2013). An overview of volcano infrasound: From Hawaiian to Plinian, local to global, Journal of Volcanology and Geothermal Research 249, 123-139, doi:10.1016/i.jvolgeores.2012.09.002

Frankel, A., S. Hough, P. Friberg, and R. Busby (1991). Observations of Loma Prieta aftershocks from a dense array in Sunnyvale, California, Bulletin of the Seismological Society of America 81, 1900-1922

Fyen, J., M. Roth, and P. W. Larsen (2014). IS37 Infrasound Station in Bardufoss, Norway, in NORSAR Scientific Report 2-2013, Semiannual Technical Summary, June 2014, Kjeller, Norway. pp. 2939. 
Gibbons, S. J. and F. Ringdal (2006). The detection of low magnitude seismic events using array-based waveform correlation, Geophysical Journal International 165, 149-166. doi:10.1111/j.1365246x.2006.02865.x

Gibbons, S. J. and F. Ringdal (2010). Detection and Analysis of Near-Surface Explosions on the Kola Peninsula, Pure and Applied Geophysics 167, 413-436, doi:10.1007/s00024-009-0038-8

Gibbons, S., T. Kværna, and F. Ringdal (2005). Monitoring of seismic events from a specific source region using a single regional array: A case study, Journal of Seismology, 9, 277-294, doi:10.1007/s10950-005-5746-7

Gibbons, S. J., F. Ringdal, and T. Kværna (2007). Joint seismic-infrasonic processing of recordings from a repeating source of atmospheric explosions, Journal of the Acoustical Society of America, 122, EL158-EL164, doi:10.1121/1.2784533

Green, D. N. and D. Bowers (2010). Estimating the detection capability of the International Monitoring System infrasound network, Journal of Geophysical Research 115, D18116, doi:10.1029/2010jd014017

Green, D. N., A. Le Pichon, L. Ceranna, and L. Evers (2010). Ground Truth Events: Assessing the Capability of Infrasound Networks Using High Resolution Data Analyses, Chapter 19 in "Infrasound Monitoring for Atmospheric Studies", Le Pichon, A., Blanc, E., and Hauchecorne, A. (eds.), Springer Science and Business Media, B. V, 599-625, doi:10.1007/978-1-4020-9508$\underline{5 \quad 19}$

Green, D. N., J. Vergoz, R. Gibson, A. Le Pichon, and L. Ceranna (2011). Infrasound radiated by the Gerdec and Chelopechene explosions: propagation along unexpected paths, Geophysical Journal International 185, 890-910, doi:10.1111/j.1365-246x.2011.04975.x

Hagerty, M. T., W.-Y. Kim, and P. Martysevich (2002). Infrasound Detection of Large Mining Blasts in Kazakhstan, in "Monitoring the Comprehensive Nuclear-Test-Ban Treaty: Data Processing and Infrasound" 1063-1079, doi:10.1007/978-3-0348-8144-9 9

Harris, D. B. (1991). A waveform correlation method for identifying quarry explosions, Bulletin of the Seismological Society of America 81, 2395-2418

Harris, D. B. and T. Kværna (2010). Superresolution with seismic arrays using empirical matched field processing, Geophysical Journal International 182, 1455-1477, doi:10.1111/j.1365246x.2010.04684.x

D. B. Harris, F. Ringdal, E. O. Kremenetskaya, S. Mykkeltveit, J. Schweitzer, T. F. Hauk, V. E. Asming, D. W. Rock, and J. P. Lewis (2003). Ground-Truth collection for mining explosions in Northern Fennoscandia and Russia, in "Proceedings of the 25th Seismic Research Review", Tucson, Arizona, September 23-25, 2003: "Nuclear Explosion Monitoring: Building the Knowledge Base", LA-UR-03-6029 - Los Alamos National Laboratory, 54-63

Hedlin, M. A. H. and K. Walker (2013). A study of infrasonic anisotropy and multipathing in the atmosphere using seismic networks, Philosophical Transactions of the Royal Society A: Mathematical, Physical and Engineering Sciences 371, doi:10.1098/rsta.2011.0542 
Hedlin, M. A. H., K. Walker, D. P. Drob, and C. D. de Groot Hedlin (2012). Infrasound: Connecting the Solid Earth, Oceans, and Atmosphere, Annual Review of Earth and Planetary Sciences 40, 327-354, doi:10.1146/annurev-earth-042711-105508

Kværna, T. and D. J. Doornbos (1986). An integrated approach to slowness analysis with arrays and three-component stations, in NORSAR Scientific Report 2-1985/1986, Semiannual Technical Summary, 1 April - 30 September 1986, 60-69, NORSAR, Kjeller, Norway.

Kværna, T., F. Ringdal (1994), Intelligent post-processing of seismic events, Annali di Geofisica 37, 309-322, doi:10.4401/ag-4209

Lalande, J. M. , O. Sèbe, M. Landès, Ph. Blanc-Benon, R. S. Matoza, A. Le Pichon, and E. Blanc (2012). Infrasound data inversion for atmospheric sounding, Geophysical Journal International 190, 687-701, doi:10.1111/j.1365-246x.2012.05518.x

Langston, C. A. (2004), Seismic ground motions from a bolide shock wave, Journal of Geophysical Research 109, B12309, doi:10.1029/2004jb003167

Le Pichon, A., J. Vergoz, P. Herry, and L. Ceranna (2008). Analyzing the detection capability of infrasound arrays in Central Europe, Journal of Geophysical Research 113, D12115, doi:10.1029/2007JD009509

Le Pichon, A., J. Vergoz, E. Blanc, J. Guilbert, L. Ceranna, L. Evers, and N. Brachet (2009). Assessing the performance of the International Monitoring System's infrasound network: Geographical coverage and temporal variabilities, Journal of Geophysical Research 114, D08112, doi: $\underline{10.1029 / 2008 J D 010907}$

Liszka, L. (1974). Long-distance propagation of infrasound from artificial sources, Journal of the Acoustical Society of America 56, 1383-1388, doi:10.1121/1.1903454

Liszka, L. (1978). Long-distance focusing of Concorde sonic boom, Journal of the Acoustical Society of America 64, 631-635, doi:10.1121/1.382024

Liszka, L., and M. A. Garcés (2002). Infrasonic Observations of the Hekla Eruption of February 26, 2000, Journal of Low Frequency Noise, Vibration, and Active Control 21, 1-8. doi:10.1260/02630920260374934

Matoza, R. S., J. Vergoz, A. Le Pichon, L. Ceranna, D. N. Green, L. G. Evers, M. Ripepe, P. Campus, L. Liszka, T. Kværna, E. Kjartansson, and Á. Höskuldsson (2011). Long-range acoustic observations of the Eyjafjallajökull eruption, Iceland, April-May 2010, Geophysical Research Letters 38, L06308, doi:10.1029/2011gl047019

MacCarthy, J. K, H. Hartse, M. Greene, and C. Rowe (2008). Using Waveform Cross-Correlation and Satellite Imagery to Identify Repeating Mine Blasts in Eastern Kazakhstan, Seismological Research Letters 79, 393-399, doi:10.1785/gssrl.79.3.393

Modrak, R. T., S. J. Arrowsmith, and D. N. Anderson (2010). A Bayesian framework for infrasound location, Geophysical Journal International 181, 399-405, doi:10.1111/i.1365246x.2010.04499.x 
Morton, E. A. and S. J. Arrowsmith (2014). The Development of Global Probabilistic Propagation Look-Up Tables for Infrasound Celerity and Back-Azimuth Deviation, Seismological Research Letters 85, 1223-1233, doi:10.1785/0220140124

Mutschlecner, J. P. and R. W. Whitaker (1999). Thermospheric Infrasound Signals, in "Proceedings of the 21st Seismic Research Symposium, Las Vegas, NV, September 21-24, 1999: Technologies for Monitoring The Comprehensive Nuclear-Test-Ban Treaty", Volume II, LA-UR-99-4700 Los Alamos National Laboratory, 151-158.

Mykkeltveit, S., F. Ringdal, T. Kvaerna, and R. W. Alewine (1990). Application of regional arrays in seismic verification research, Bulletin of the Seismological Society of America 80, 1777-1800.

Negraru, P. T., P. Golden, and E. T. Herrin (2010). Infrasound Propagation in the "Zone of Silence", Seismological Research Letters 81, 614-624, doi:10.1785/gssrl.81.4.614

Nippress, A., D. N. Green, O. E. Marcillo, and S. J. Arrowsmith (2014). Generating regional infrasound celerity-range models using ground-truth information and the implications for event location, Geophysical Journal International 197, 1154-1165. doi:10.1093/gii/ggu049

Sorrells, G. G. , E. T. Herrin, and J. L. Bonner (1997). Construction of regional ground truth databases using seismic and infrasound data, Seismological Research Letters 68, 743-752, doi:10.1785/gssrl.68.5.743

Stump, B. W., Hedlin, M. A. H., Pearson, D. C., and Hsu, V. (2002). Characterization of mining explosions at regional distances: Implications with the International Monitoring System, Reviews of Geophysics 40, 1011+, doi:10.1029/1998rg000048

Sutherland, L. C. and H. E. Bass (2004). Atmospheric absorption in the atmosphere up to $160 \mathrm{~km}$, The Journal of the Acoustical Society of America 115, 1012-1032, doi:10.1121/1.1631937

Tailpied, D., A. Le Pichon, E. Marchetti, M. Ripepe, M. Kallel, L. Ceranna, and N. Brachet (2013). Remote Infrasound Monitoring of Mount Etna: Observed and Predicted Network Detection Capability, Inframatics 2, 1-11, doi:10.4236/inframatics.2013.21001

Vinogradov, Y. and F. Ringdal (2003). Analysis of infrasound data recorded at the Apatity array, in NORSAR Scientific Report 1-2003, Semiannual Technical Summary, February 2003, 68-77, NORSAR, Kjeller, Norway.

Wessel, P. and W. H. F. Smith (1995). New version of the generic mapping tools released, EOS Transactions, American Geophysical Union 76, no. 33, 329.

Whitaker, R. W. and J. P. Mutschlecner (2008). A comparison of infrasound signals refracted from stratospheric and thermospheric altitudes, Journal of Geophysical Research 113, D08117, doi:10.1029/2007jd008852 